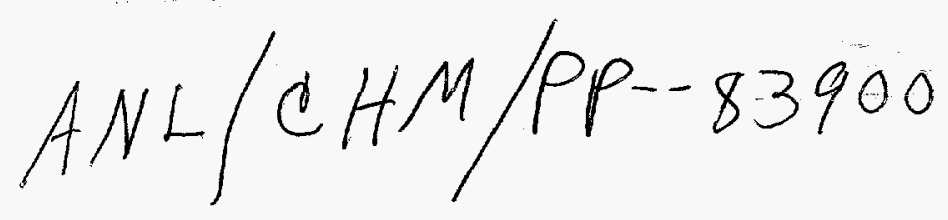

\title{
THE DISCOVERY OF FULLERENES IN THE 1.85 BILLION-YEAR-OLD SUDBURY METEORITE CRATER
}

\author{
Luann Becker and Jeffrey L. Bada \\ Scripps Institution of Oceanography, University of California at San Diego, La Jolla, CA 92093
}

Randall E. Winans and Jerry E. Hunt

Chemistry Division, Argonne National Laboratory. Argonne, IL 60439

Ted E. Bunch

NASA Ames Research Center, Space Science Division, Moffett Field, CA 94035

Bevan M. French

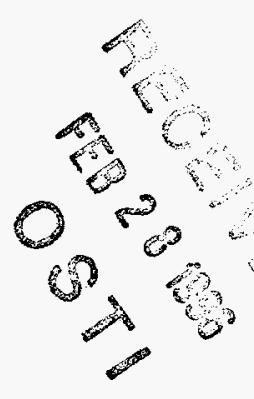

NASA Headquarters, Code SLC, 300 E Street, Southwest Washington, D.C. 20546

Fullerenes have been identified in rock samples from a 1.85 billion-year-old meteorite impact crater by a team of scientists from Scripps Institution of Oceanography, Argonne National Laboratory, and NASA. Fullerenes, with the formulae $\mathrm{C}_{60}$ and $\mathrm{C}_{70}$, are a recently discovered new form of carbon that is synthesized under very special conditions in the absence of air. Dr. Randall Winans and Dr. Jerry Hunt of Argonne National Laboratory and Luann Becker of Scripps Institution of Oceanography identified fullerenes in extracts of the rock samples using mass spectrometric techniques in Argonne's Chemistry Division. The methods used were developed at ANL in a Basic Energy Sciences - Chemical Sciences program in Fundamental Coal Chemistry. These fullerenes were likely synthesized within the impact plume from carbon contained in the meteorite. Few other types of organic carbon are found in these samples. The fact that the fullerenes survived for such a long period of time is surprising and, therefore, they must have been protected from degradation by air. These fullerenes are associated with sulfur, which may have protected them. This is the largest known deposit of naturally occurring fullerenes.

The discovery and synthesis of fullerenes, and their unusual stability against photodissociation and thermal degradation, soon led to the hypothesis that fullerenes may be ubiquitous and abundant in 
the universe, particularly in the outflows of carbon stars. Fullerene molecules, or perhaps their hydrogenated counterparts (fulleranes), have been suggested to be carriers of visible diffuse interstellar bands, although, so far, spectroscopic searches for fullerenes and fulleranes in space have led to negative results. Fullerenes have been recently reported in impact residues in a small crater on NASA's Long Duration Exposure Facility. Several studies have investigated fullerenes in meteorites, but so far none have been detected. On the Earth, natural fullerenes have been identified in fulgurite, a glassy rock that forms where lightning hits the ground, and shungite, a highly metamorphosed carbon-rich rock within Precambrian sediments. Based on these reported terrestrial occurrences, it would appear that fullerenes are not a ubiquitous form of carbon on Earth.

Because fullerenes form under highly energetic conditions and at intense temperatures and pressures, we decided to investigate meteorite impact deposits on Earth for the presence of natural fullerenes. We report here the discovery of fullerenes $\left(C_{60}\right.$ and $\left.C_{70}\right)$ from the Sudbury impact structure in Ontario, Canada. The fullerenes were identified in separate samples by laser desorption timeof-flight (TOF) methods and also by high-resolution electron-ionization mass spectrometry (EIMS).

The Sudbury structure in Ontario, Canada is an elliptical basin $60 \mathrm{~km}$ long and $27 \mathrm{~km}$ wide, elongated in an east-northeast direction. The Onaping Formation differs from the ejecta at other impact craters in being highly carbonaceous (total organic carbon $\sim 0.5$ to $1.0 \%$ ), especially in the upper parts of the formation. The source of the carbon has long been (and still is) a mystery.

We examined three samples of the carbon-rich upper unit, the so-called "Black Tuff." Samples were extracted and prepared for analysis using standard techniques. Onaping extracts were analyzed by laser desorption and laser desorption/postionization time-of-flight (TOF) mass spectrometric techniques. The laser desorption (reflectron) TOF mass spectrum for one of the extracts (Fig. 1) shows a strong peak at $\mathrm{m} / \mathrm{z} 720 \mathrm{amu}$, which corresponds to $\mathrm{C}_{60^{+}}$, and a less prominent peak at $\mathrm{m} / \mathrm{z}$ $840 \mathrm{amu}$, which corresponds to $C_{70^{+}}$. Also apparent are peaks (see insert Fig. 1) at $\mathrm{m} / \mathrm{z} 720,721$, and $722 \mathrm{amu}$, which are characteristic of the isotopic distribution of $\mathrm{C}_{60}$. The spectrum consists almost entirely of $\mathrm{C}_{60^{+}}$, and the observed $\mathrm{C}_{60^{+}} / \mathrm{C}_{70^{+}}$peak ratio is 15 . 
To further confirm the identification of $\mathrm{C}_{60}$ in the Onaping Formation, we investigated an extract by electron-ionization mass spectrometry (EIMS). Three peaks were seen at $m / z=784,785$, and 786 amu, but no peaks were evident in the 720 amu region. This was surprising considering the laser mass spectrometry results that indicate the presence of fullerenes and elemental sulfur only. We realized that $\mathrm{C}_{60}$ could be reacting with the sulfur during the ionization process, resulting in a mass spectrum for $\mathrm{C}_{60} \mathrm{~S}_{2}(\mathrm{~m} / \mathrm{z}=784 \mathrm{amu})$.

We redissolved the sample extract in $\mathrm{CS}_{2}$ and stirred the solution in the presence of copper at room temperature overnight in order to remove sulfur from the extract. The mass spectrum (Fig. 2) of the treated solution revealed three peaks at 719.9985, 721.0046, and 722.0197 amu corresponding to ${ }^{12} \mathrm{C}_{60^{+}},{ }^{12} \mathrm{C}_{59}{ }^{13} \mathrm{C}_{+}$, and ${ }^{12} \mathrm{C}_{58}{ }^{13} \mathrm{C}_{2}$, respectively. The detection of $\mathrm{C}_{60}$ in the treated extract using EIMS provides further evidence that $C_{60}$ is present in the samples. The ratios of the $\mathrm{C}_{60}$ isotopic mass peaks are 1:0.71:0.34, suggesting a possible enrichment of ${ }^{13} \mathrm{C}$. Independent measurements (see inset Fig. 1) also showed a similar ${ }^{13} \mathrm{C}$ enrichment. Isotopic compositions measured by stepped combustion have shown that synthetic $C_{60}$ is slightly enriched in ${ }^{13} \mathrm{C}$ in comparison to the graphite rods from which it was made. The ${ }^{13} \mathrm{C}$ enrichment we have found in the Sudbury $\mathrm{C}_{60}$ may be the result of isotopic fractionation during the synthesis of fullerenes in the impact event or ${ }^{13} \mathrm{C}$ enrichment in the source carbon.

The distributions of carbon and sulfur in the Sudbury structure were likely the result of an impact event. The abundance of sedimentary carbon in the Sudbury target rocks is much less than $1 \%$, with an additional $3-5 \%$ in some rare, thin-bedded, carbonate-bearing sediments, thus eliminating the possibility of a significant carbon source from these surface rocks. Thus the combustion of these carbonaceous surface rocks, especially at the low atmospheric oxygen partial pressures characteristic on the Earth 1.85 billion years ago, seems to be an unlikely mechanism of formation for the Sudbury fullerenes. The carbon that was eventually transformed into fullerenes likely came from a carbon-rich meteor. Fullerenes may have been present in the impacting meteorite, although this seems unlikely because fullerenes have not been detected in carbonaceous chondrites and are thought improbable to be found there because the formation of fullerenes is inhibited by the presence of hydrogen, which 
is abundant in cosmochemical environments. Another possibility is that fullerenes may have formed as a result of pyrolysis of organic matter present in the meteorite.

Fullerenes degrade quickly at fairly low temperatures when exposed to air. The survival of fullerenes found in the 1.85 billion-year-old Sudbury deposits clearly requires storage in an environment of low oxygen. Although low-oxygen levels were present in the Earth's atmosphere at the time of the Sudbury fullerene synthesis, oxygen probably reached present atmospheric levels soon after (a few hundred million years) deposition. The presence of diagenetic sulfides indicates that the environment in which the Onaping rocks were deposited had low-oxygen and high-sulfur concentrations. Perhaps the fullerenes in the Onaping rocks were protected from oxidation by the surrounding sulfide-silicate matrix in which they are contained, allowing fullerenes to survive to the present.

Because of the extensive area of the Sudbury deposits, this may be one of the largest natural occurrences of fullerenes found so far on Earth.

\section{Figure Captions}

Figure 1. Laser desorption (reflectron) time-of-flight (TOF) mass spectrum showing a strong peak at $\mathrm{m} / \mathrm{z} 720$ amu, and a less prominent peak at $\mathrm{m} / \mathrm{z} 840 \mathrm{amu}$. An inset of the $\mathrm{C}_{60}+$ peak shows the isotopic distributions for $\mathrm{m} / \mathrm{z} 720, \mathrm{~m} / \mathrm{z} 721$, and $\mathrm{m} / \mathrm{z} 722 \mathrm{amu}(\mathrm{m} / \Delta \mathrm{m}-800)$.

Figure 2. Electron ionization mass spectrum (EIMS) $(\mathrm{m} / \Delta \mathrm{m} \sim 1000)$ of $\mathrm{C}_{60^{+}}$revealed three peaks at $719.9985,721.0046$, and 722.0197 amu corresponding to ${ }^{12} \mathrm{C}_{60^{+}},{ }^{12} \mathrm{C}_{59}{ }^{13} \mathrm{C}_{+}$, and ${ }^{12} \mathrm{C}_{58}{ }^{13} \mathrm{C}_{2^{+}}$, respectively.

\section{DISCLAIMER}

This report was prepared as an account of work sponsored by an agency of the United States Government. Neither the United States Government nor any agency thereof, nor any of their employees, makes any warranty, express or implied, or assumes any legal liability or responsibility for the accuracy, completeness, or usefulness of any information, apparatus, product, or process disclosed, or represents that its use would not infringe privately owned rights. Reference herein to any specific commercial product, process, or service by trade name, trademark, manufacturer, or otherwise does not necessarily constitute or imply its endorsement, recommendation, or favoring by the United States Government or any agency thereof. The views and opinions of authors expressed herein do not necessarily state or reflect those of the United States Government or any agency thereof. 

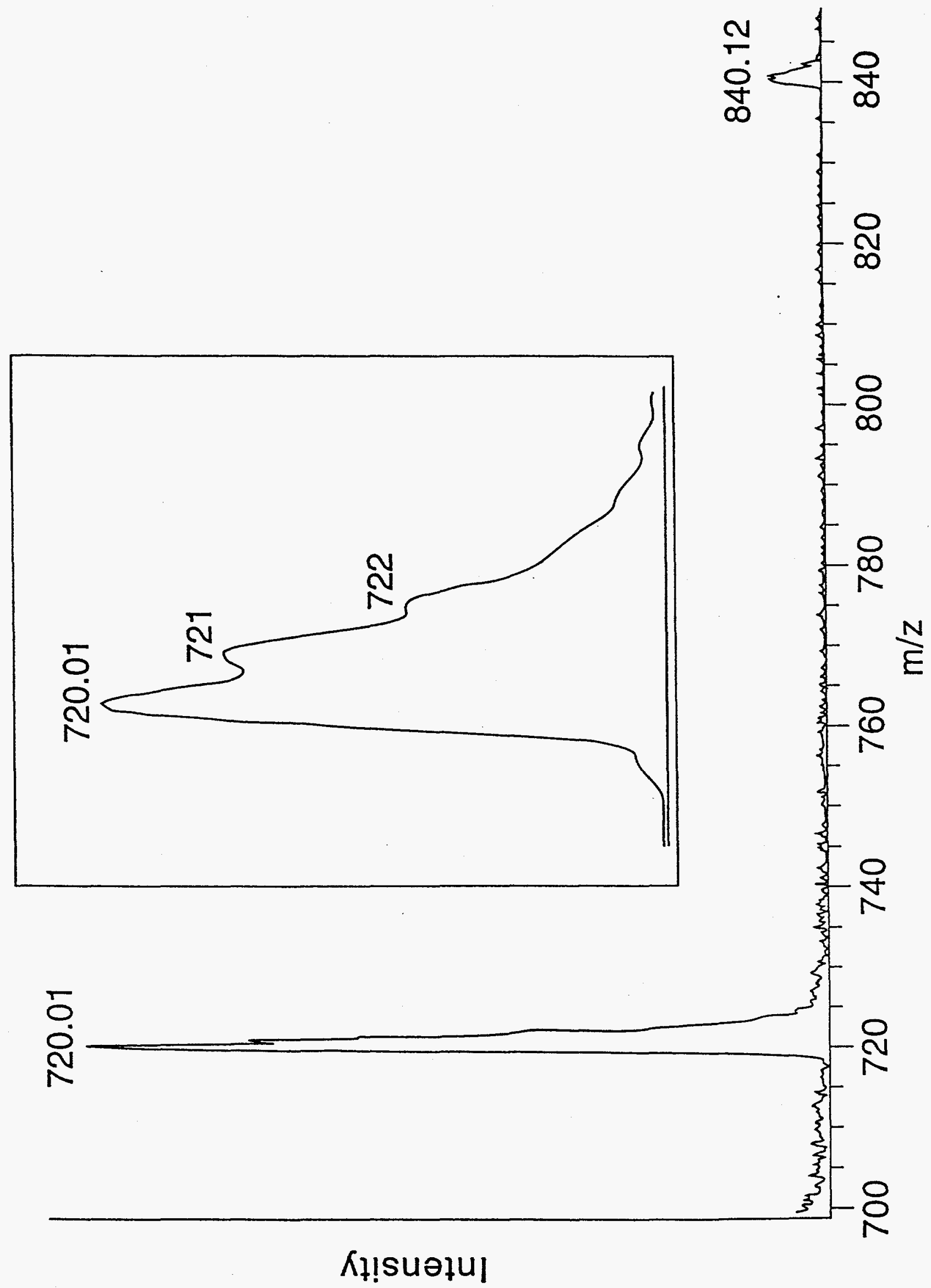


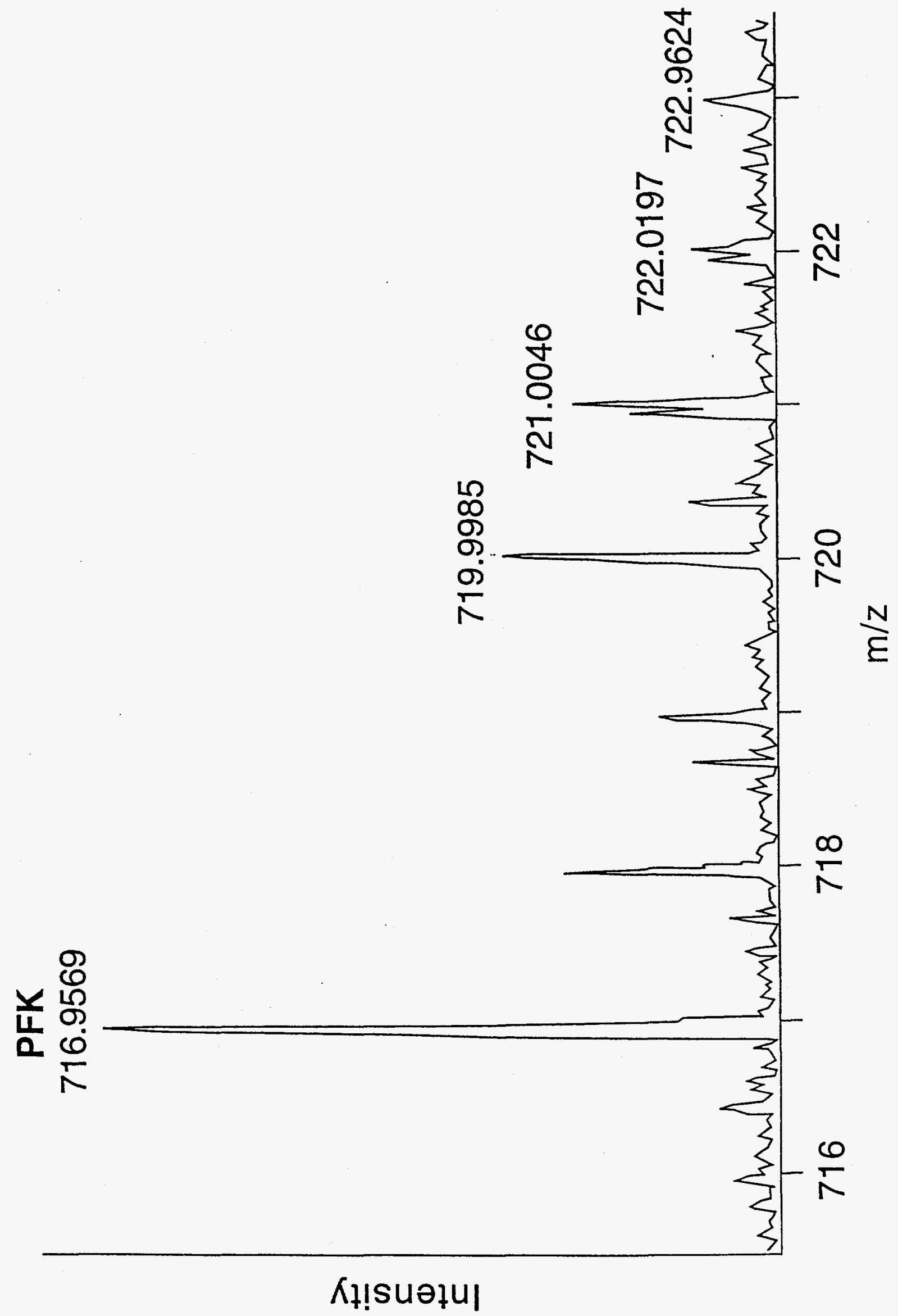

